\title{
Enzymatic mechanism of the tumoricidal action of 4-iodo-3-nitrobenzamide
}

\author{
ERNEST KUN, JEROME MENDELEYEV, ALAEDDIN HAKAM and EVA KIRSTEN
}

\begin{abstract}
UCSF Helen Diller Family Comprehensive Cancer Center and the Department of Cellular and Molecular Pharmacology, University of California, San Francisco, School of Medicine, San Francisco, CA 94143, USA
\end{abstract}

Received March 31, 2009; Accepted June 15, 2009

DOI: $10.3892 / \mathrm{mmr}$ 00000165

\begin{abstract}
Activation of the prodrug 4-iodo-3-nitrobenzamide critically depends on the cellular reducing system specific to cancer cells. In non-malignant cells, reduction of this prodrug to the non-toxic amine occurs by the flavoprotein of complex I of mitochondria receiving $\mathrm{Mg}^{2+}$-ATP-dependent reducing equivalents from NADH to NADPH via pyridine nucleotide transhydrogenation. This hydride transfer is deficient in malignant cells; therefore, the lethal synthesis of 4-iodo-3nitrosobenzamide takes place selectively. Enzymatic evidence for this mechanism has been provided by cellular studies with lysolecithin-permeabilized cells and cell fractions, which have identified the defect in transhydrogenation in neoplastic cells to be located at the energy transfer site. Confirming previous results, the present study demonstrates the validity of the selective tumoricidal action of the prodrug in cell cultures.
\end{abstract}

\section{Introduction}

Identification of the chemical and enzymatic (by cytochrome P-450) oxidation of Aryl amines to their first oxidized product, nitroso Aryls (1), marked a significant milestone in our investigations aimed at the chemotherapy of neoplastic diseases. We showed that C-nitroso Aryls induced precipitous cell death in tumor cells (2), an effect which was so rapid that tumor cells exposed to these drugs autolysed overnight in culture dishes. However, the cell killing by synthetic nitroso Aryls of neoplastic cells was only 2- to 3-fold greater than that observed in non-malignant cells, therefore exhibiting in vivo toxicity. For these reasons, we developed non-toxic nitroso precursors that are enzymatically reduced to the cytotoxic nitroso derivative in neoplastic cells only. A prototype nitroso

Correspondence to: Professor Ernest Kun, Helen Diller Family Comprehensive Cancer Center, University of California, San Francisco, San Francisco, CA 94143, USA

E-mail: ernestkun@comcast.net

Key words: xenobiotic metabolism of $\mathrm{R}-\mathrm{NO}_{2}$, lethal synthesis, $\mathrm{Mg}^{2+}-$ ATP-dependent pyridine nucleotide transhydrogenation, lysolecithin cell permeabilization precursor is 4-iodo-3-nitrobenzamide (4-I-3 $\left.\mathrm{NO}_{2} \mathrm{BA}\right)(3,4)$. It must be emphasized that the vicinal iodo-nitro substitution in 4-I-3 $\mathrm{NO}_{2} \mathrm{BA}$ eliminates a direct poly(ADP-ribose) polymerase (PARP-1, E.C. 2.4.2.30) inhibitory action of this benzamide derivative. PARP-1 inhibitory propensity is common to numerous benzamides, which compete with the nicotinamide moiety of $\mathrm{NAD}^{+}(5)$. The acid-amide group in $4-\mathrm{I}-3 \mathrm{NO}_{2} \mathrm{BA}$ enhances rapid cellular penetration over the carboxylate $(3,4)$, which is the reason for retaining the acid-amide group.

The fate of the cell type exposed to $4-\mathrm{I}-3 \mathrm{NO}_{2} \mathrm{BA}$ depends on its xenobiotic metabolism: cancer cells are killed while non-malignant cells experience no harmful consequences. The predictable xenobiotic metabolism of $4-\mathrm{I}-3 \mathrm{NO}_{2} \mathrm{BA}$ is its reduction to the corresponding non-toxic $4-\mathrm{I}-3 \mathrm{NH}_{2} \mathrm{BA}$, which is hydroxylated and glucuronidated in vivo, followed by urinary excretion $(6,7)$. This innocuous pathway critically depends on the enzymatic reduction of $\mathrm{R}-\mathrm{NO}_{2}$ to $\mathrm{R}-\mathrm{NH}_{2}$, which hinges on the catalytic activity of the multifunctional mitochondrial flavoprotein of complex I. The energy coupled reduction of this flavoprotein by NADPH depends on the transhydrogenation of $\mathrm{NADP}^{+}$by NADH (8). Since we observed an as yet unspecified bioenergetic defect in cancer cells (9), we predicted that this defect may impede the OXPHOS-dependent reduction of $\mathrm{R}^{-\mathrm{NO}_{2}}$ to $\mathrm{R}^{-\mathrm{NH}_{2}}$ in tumor cells. Energy-linked pyridine nucleotide transhydrogenation has been extensively studied in mitochondria isolated by the sucrose gradient centrifugation technique and in mitochondrial fragments and purified systems. However, the sonication-dependent isolation technique of submitochondrial fragments (8) failed to separate soluble and particle-bound components of the transhydrogenase and produced truncated fragments. On the other hand, treatment of intact cells with lysolecithin $(9,10)$ allowed us to study the regulation of transhydrogenation in nearly intact cells, a feat which has not been accomplished thus far, allowing us to pinpoint the difference in transhydrogenation between malignant and non-malignant cells at the particulate fraction, containing components of energy transduction. These results confirm the findings of previous studies (9), which showed defective bioenergetics in malignant cells in cell cultures and in vivo.

Since the enzymatic reduction of $\mathrm{R}-\mathrm{NO}_{2}$ occurs through the flavoprotein of complex I, which receives reducing equivalents by way of the energy-dependent formation of NADPH from NADH, we concluded that the metabolic specificity of tumor cell killing by $4-\mathrm{I}-3 \mathrm{NO}_{2} \mathrm{BA}$ is directly attributable 
to its reduction to 4-I-3NOBA. The present study provides experimental evidence to support this enzymatic mechanism.

\section{Materials and methods}

Synthesis and chemical analyses. The synthesis of 4-I-3$\mathrm{NO}_{2} \mathrm{BA}$ and chemical methods of analyses were identical to those previously reported $(3,4,6,7)$. Lysolecithin (LL) was purchased from Sigma-Aldrich, and 3-acetylpyridine adenine dinucleotide (reduced form) (AcNADH) was from OYC Americas (Andover, MA, USA).

Cell culture. Cell culture methods for CV-1 $(9,10)$ and Eras 20 cells were identical to those previously reported (11). All cancer cells, upon prolonged subculturing, undergo varying degrees of senescence. This modifies their malignant phenotype (12). In contrast, Eras 20 cells obtained by the transformation of bovine aortic endothelial cells (11) for 25 years showed no signs of senescence, and for this reason were used as an invariable neoplastic prototype cell.

Permeabilized cells and cell fractions. Permeabilized cells and cell fractions were prepared as previously reported $(9,10)$. Briefly, CV-1 and Eras 20 cells were detached and counted from appropriate cultures, and cells were suspended in a standard buffer consisting of $150 \mathrm{mM}$ sucrose, $80 \mathrm{mM} \mathrm{KCl}$ and 35 $\mathrm{mM}$ HEPES buffer of $\mathrm{pH}$ 7.4. The cell number/buffer volume ratio was $10^{6}$ cells $/ 100 \mu \mathrm{l}$ buffer, to which $0.21 \mathrm{mg} / \mathrm{ml} \mathrm{LL}$ was added from an LL stock solution $(1 \mathrm{mg} / \mathrm{ml})$. Cell suspensions were kept on ice $\left(0-4^{\circ} \mathrm{C}\right)$ during this manipulation. Cell fractions [soluble SU and particulate $\left(\mathrm{M}_{\mathrm{X}}\right)$ ] (10) were prepared in Eppendorf centrifuge tubes by sedimentation (Eppendorf model $54155 \mathrm{R}$ centrifuge at $4^{\circ} \mathrm{C}$ at $6600 \mathrm{rpm}$ for $6 \mathrm{~min}$ ). After the quantitative removal of the $\mathrm{SU}$ fraction, the $\mathrm{M}_{\mathrm{X}}$ sediment was resuspended in the LL standard buffer (see above) at a density of $10^{6}$ cell equivalents/100 $\mu$. This technique enabled us to dispense $10^{6}$ cell equivalents for each spectrophotometric enzyme assay.

Spectrophotometric transhydrogenase tests. Two assay systems were developed. The first contained $0.2 \mathrm{mM}$ AcNADH, $0.38 \mathrm{mM} \mathrm{NADP}^{+}, 1 \mathrm{mM} \mathrm{Mg}{ }^{2+}$-ATP, $10 \mathrm{mM}$ deoxyglucose (9) and LL-cells (or cell fractions) equivalent to $10^{6}$ cells in Tris- $\mathrm{HCl}(25 \mathrm{mM}, \mathrm{pH} 7.5)$ in a volume of $1.0 \mathrm{ml}$ (Fig. 1A). $\mathrm{Mg}^{2+}$-ATP was an equimolar mixture of $1 \mathrm{mM} \mathrm{MgCl}_{2}$ and 1 mM ATP. The $\mathrm{Mg}^{2+}$ complex of ATP was an absolute requirement for the transhydrogenation of AcNADH to NADP+; ATP alone was ineffective. Tests were performed in a Shimadzu UV-1650 PC system (10) in $1 \mathrm{ml}$ quartz cuvettes of $1 \mathrm{~cm}$ light path and $1 \mathrm{ml}$ volume at $25^{\circ} \mathrm{C}$. The rates of NADPH formation were followed at $340 \mathrm{~nm}$, and the generation of AcNADH at $268 \mathrm{~nm}$.

In the second assay system, AcNADH was omitted and replaced by cellular $\mathrm{NAD}^{+}$and reducing substrates, both present in LL-cell suspensions (Fig. 1B), thus representing a metabolically generated reducing equivalent producing system. The comparison of two transhydrogenation assays in whole cells appeared necessary to establish that no rate limiting factors in the whole cells interfered with the $\mathrm{V}_{\max }$ of hydride transfer, and the assays actually measured only the rates of transhydrogenation. The combination of both assays makes this method applicable to any cell type.

Quantitative assays. Quantitative assays for the cytocidal action of 4-I- $3 \mathrm{NO}_{2} \mathrm{BA}$ were carried out as previously reported $(3,4)$.

\section{Results and Discussion}

Rates of NADPH formation by LL permeabilized cells determined by added AcNADH (Fig. 1A) or metabolically generated cellular NADH (Fig. 1B) are presented in Fig. 1. It is apparent that both test systems yielded nearly identical $\mathrm{V}_{\max }$ rates $(n=4, S D \pm 8 \%)$ when suspensions of non-malignant $C V-1$ cells were compared. The agreement of the two transhydrogenase tests indicates that the generation of intracellular NADH as a precursor of NADPH or the availability of AcNADH is not rate limiting in transhydrogenation. The exact enzymatic reaction mechanism that yielded metabolically-generated cellular NADH capable of reducing $\mathrm{NADP}^{+}$is not known and is the subject of further investigation, particularly since the $\mathrm{NAD}^{+}$-reducing metabolite may vary in various cell types and could contribute to cellular metabolic specificity.

According to the perspective of current studies, it is evident in Fig. 1 that Eras 20 cells exhibit only marginal $\mathrm{Mg}^{2+}$-ATPdependent $\mathrm{NADH} \rightarrow \mathrm{NADP}^{+}$transhydrogenase activity.

The nature of this defective transhydrogenation in Eras 20 cells is illustrated in Fig. 2A and B. As we previously reported $(9,10)$, rapid centrifugation of an LL-permeabilized cell suspension separates a particulate $\left(\mathrm{M}_{\mathrm{X}}\right)$ fraction containing nuclei and perinuclearly located mitochondria and a soluble SU fraction (10). The $M_{X}$ fraction, which retains subcellular structures noted by electron microscopy (9) and the soluble SU fraction, both prepared from CV-1 cells, each had marginal energy-dependent transhydrogenase activity when tested separately (Fig. 2A). However, their recombination yielded maximal enzymatic rates (Fig. 2A), demonstrating that the LL-fractionation technique of $\mathrm{CV}-1$ cells retained protein sites in both fractions. Upon recombination, these yielded full transhydrogenase activity to $\mathrm{NADP}^{+}$present in unfractionated permeabilized cells.

Fig. 2B illustrates the results of enzymatic tests conducted with cell fractions prepared from Eras 20 cells combined with those prepared from CV-1 cells. The SU fraction of CV-1 cells yielded only $30 \%$ of transhydrogenase activity when combined with the $M_{X}$ fraction of Eras 20 cells (lower curve of Fig. 2B), while the SU fraction of Eras 20 cells when combined with the $M_{X}$ fraction of $C V-1$ cells recovered full transhydrogenase activity. As a complement to these tests, we determined the 'energy-independent' $\mathrm{H}$ transfer from NADPH to AcNAD ${ }^{+}$ assayed as the reduction of $\mathrm{AcNAD}^{+}$by NADPH at $268 \mathrm{~nm}$, and found them to be equally active in the SU fractions of CV-1 and Eras 20 cells (data not shown). The sum of these results demonstrates that the pyridine nucleotide transhydrogenase enzyme in the SU fractions of CV-1 and Eras 20 cells was equal. Consequently, depressed $\mathrm{Mg}^{2+}$-ATP-dependent transhydrogenase activity in combined $\mathrm{SU}$ fractions from CV-1 cells and $M_{X}$ fractions from Eras 20 cells (Fig. 2B) clearly indicates that the major enzymatic defect is in the $M_{X}$ fraction of Eras 20 cells. This defect results in an inhibition 

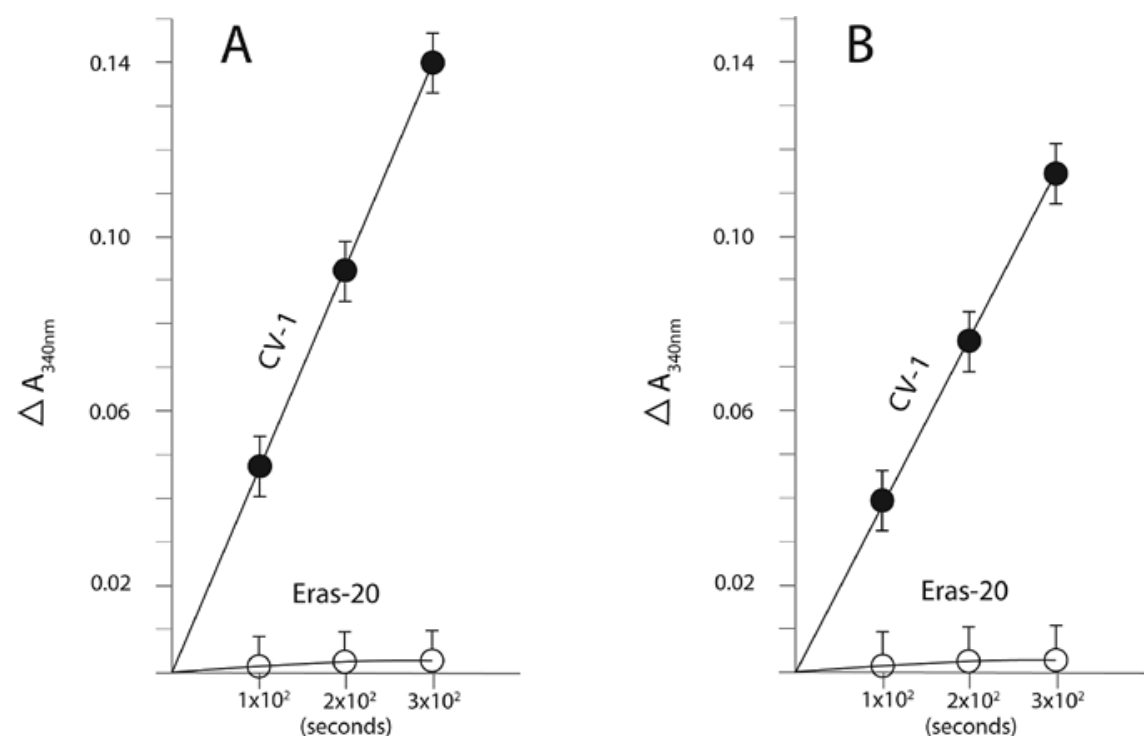

Figure 1. (A) The time course of $\mathrm{Mg}^{2+}-\mathrm{ATP}-\mathrm{dependent} \mathrm{NADPH}$ formation per $10^{6}$ cells is determined by added AcNADH as an $\mathrm{H}$ donor in lysolecithinpermeabilized cells (see Materials and methods). As in all spectrophotometric assays, a $\Delta \mathrm{A}_{340}$ of 0.01 is equal to $16 \mathrm{pmols}$ of $\mathrm{NADPH}(\mathrm{n}=4$, $\mathrm{SD} \pm 6 \%$ ). (B) The test system used is identical to that of A, except that no AcNADH was added and reducing equivalents were generated from cellular substrates and cellular $\mathrm{NAD}^{+}$present in $10^{6}$ permeabilized cells (Materials and methods) $(\mathrm{n}=4, \mathrm{SD} \pm 5 \%)$.
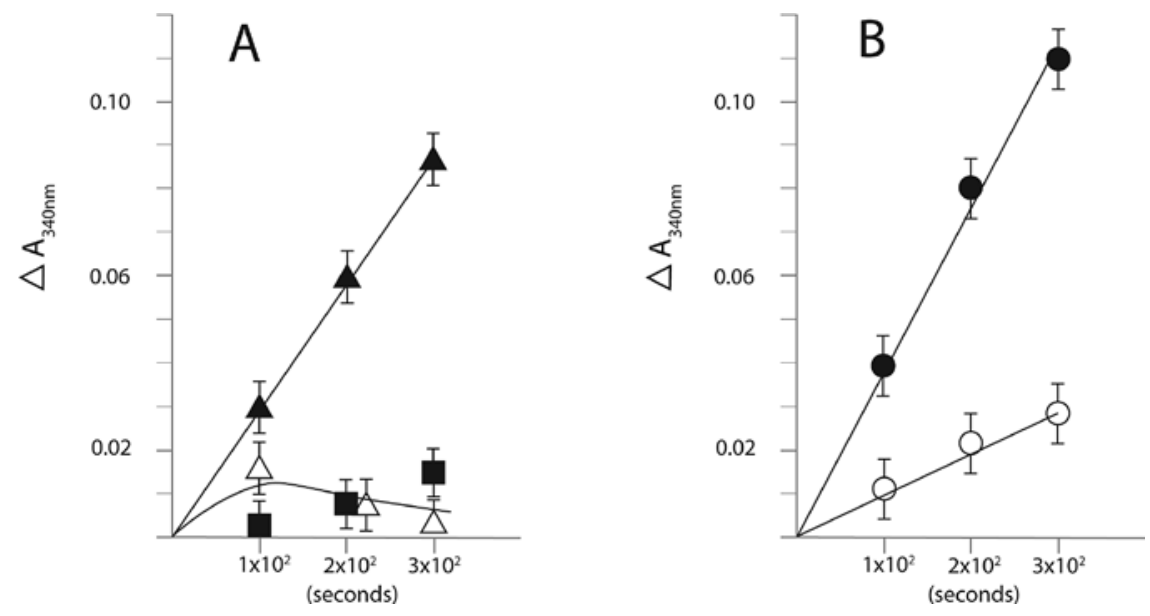

Figure 2. (A) Rates of $\mathrm{Mg}^{2+}$-ATP-dependent NADPH formation of added NADP+ in separate centrifugal fractions of $\mathrm{CV}-1$ cells $\left(\mathrm{SU}, \mathbf{-} ; \mathrm{M}_{\mathrm{X}}, \triangle\right)$ and their combination ( $\mathbf{\Lambda}$ ), calculated per $10^{6}$ cell equivalents $\left(\mathrm{n}=4, \mathrm{SD} \pm 6 \%\right.$ ). (B) Rates of $\mathrm{Mg}^{2+}$-ATP-dependent NADPH formation in combination with $\mathrm{M}_{\mathrm{X}}$ fractions of Eras 20 cells and SU fractions of CV-1 cells (०) and in combination with $\mathrm{M}_{\mathrm{X}}$ fractions of $\mathrm{CV}-1$ cells and SU fractions of Eras 20 cells $(\bullet)(n=4, \mathrm{SD} \pm 7 \%)$.

of approximately $70 \%$ of transhydrogenation (compare curves in Fig. 2B). Loss of $70 \%$ activity is apparently enough for the accumulation of the cytocidal nitroso species in tumor cells.

It is of interest that the requirement of inhibition of cellular respiration by $\mathrm{CN}^{-}$as reported by some investigators (8) was unnecessary for the assay of $\mathrm{Mg}^{2+}$-ATP-dependent transhydrogenation in the LL-cellular system (Figs. 1 and 2), indicating that the increased maintenance of cell structures favors the effectivity of $\mathrm{Mg}^{2+}$-ATP.

The requirement of $\mathrm{Mg}^{2+}$-ATP for the $\mathrm{NADH} \rightarrow \mathrm{NADP}^{+}$ transhydrogenase reaction in LL cells poses some unresolved questions in cellular bioenergetics, since it is unclear why external $\mathrm{Mg}^{2+}$-ATP is necessary in cells where OXPHOS is intact (e.g., in CV-1 cells). Externally added $\mathrm{Mg}^{2+}$-ATP to this system appears to imply a biochemical link between mito- chondrial ATP synthase and extramitochondrial $\mathrm{Mg}^{2+}$-ATP, where ATP is most likely to be derived from glycolytic ATP synthesis. This is a problem in cellular bioenergetics that is the subject of our further studies. However, the unavailability of details regarding the interplay of mitochondrial and extramitochondrial ATP generating systems does not interfere with the interpretation of the mechanisms of the lethal synthesis of iodonitrosobenzamide from $4-\mathrm{I}-3 \mathrm{NO}_{2} \mathrm{BA}$ prodrug in cancer cells. This tumoricidal mechanism involves first the generation of the nitrosylating species $(3,4)$, and also that of GS-sulfinic acid without deiodination. GS-sulfinic acid was recently shown to be the most potent inhibitor of the ubiquitous GSH-transferase (13). This transferase can act on nitrosylated targets of the prodrug, thereby eliminating cytocidal effectivity. Inhibition of the transferase therefore potentiates the action of the prodrug. 


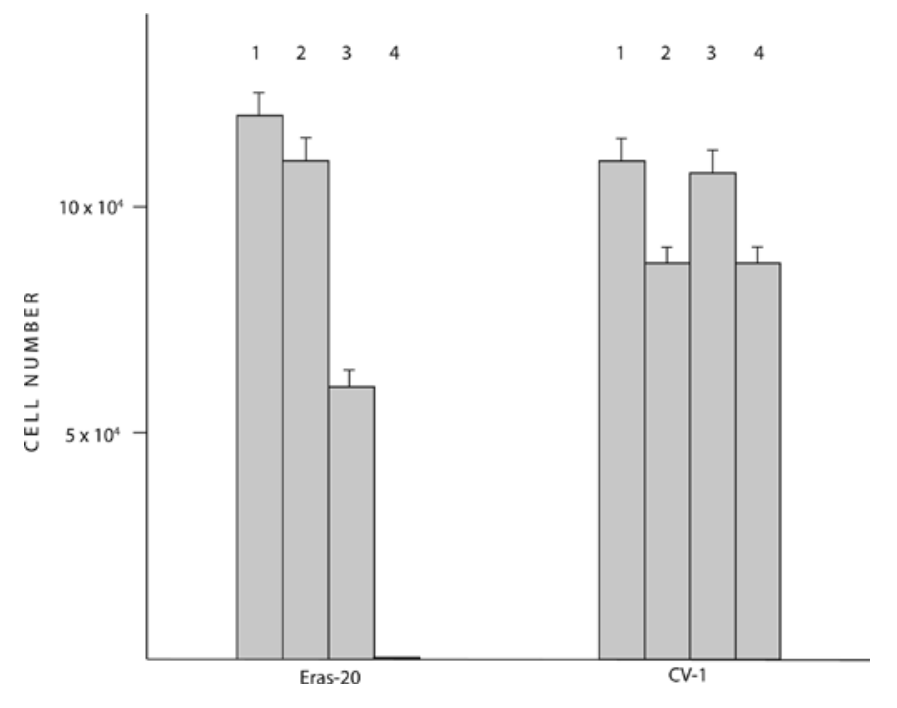

Figure 3. Cell survival assays of Eras 20 and CV-1 cells exposed for 2 days to: 1, no drugs; 2, $0.1 \mathrm{mM}$ buthionine sulfoximine (BSO); 3, $40 \mu \mathrm{M} 4-\mathrm{I}-3 \mathrm{NO}_{2} \mathrm{BA}$; 4, $0.1 \mathrm{mM}$ BSO $+40 \mu \mathrm{M} 4-\mathrm{I}-3 \mathrm{NO}_{2} \mathrm{BA}(\mathrm{n}=4, \mathrm{SD} \pm 12 \%)$.

The deletion of $\mathrm{Mg}^{2+}$-ATP-dependent transhydrogenation as noted in cancer cells also inhibits enzymatic GSSG reduction (8), thereby depleting cellular GSH, which also contributes to the tumoricidal mechanism of the prodrug.

Translating enzymologic experiments (Figs. 1 and 2) to a cell culture model, we determined the survival of Eras 20 and $\mathrm{CV}-1$ cells exposed for 2 consecutive days to $40 \mu \mathrm{M} 4-\mathrm{I}-3 \mathrm{NO}_{2} \mathrm{BA}$ alone and in combination with $0.1 \mathrm{mM}$ buthionine sulfoximine (BSO), a known inhibitor of GSH synthesis (3). As noted in Fig. 3, BSO alone had only a small effect on the cell count of Eras 20 cells, while the prodrug alone depressed cell numbers by $40-50 \%$ and a combination of these substances depressed the cell count to near zero, in agreement with previous results $(3,4)$. Induced necrosis-specific protease, which halves PARP-1 polypeptide (4) and the alkylation of protein nucleophiles [PARP-1 and glyceraldehyde-3-phosphate dehydrogenase (GAPDH, E.C. 1.2.1.12)], explains this tumoricidal action (4). On the other hand, CV-1 cells, apart from a small depression of cellular growth due to the effect of BSO alone, remained viable. The rapidity of induction of tumor necrosis by the nitrosylating reduction product of 4-iodo-3-nitrobenzamide greatly diminishes the development of drug resistance in tumor cells, which are autolysed (Fig. 3) within hours (2).

The fundamental mechanism of the tumoricidal action of 4-I-3- $\mathrm{NO}_{2} \mathrm{BA}$ is the lethal synthesis of the nitroso metabolite, a process which takes advantage of a relatively small phenotypic aberration in tumors: a defect in a specific step of energy transfer in pyridine nucleotide transhydrogenation that would have gone unnoticed had only the gene products of normal vs. tumor cells been compared. The principle of lethal synthesis is not new, as we identified a specific stereoisomer of fluorocitrate that is a powerful neurotoxin (14) metabolically generated from the innocuous F-acetate. Accurate analysis of tumor- specific metabolism has led to the discovery of the new mode of chemotherapy described in this study, illustrating the promising future of this aspect of cancer pathology.

\section{Acknowledgements}

We gratefully acknowledge the editorial help of Clementina Moya Kun and Albert Kun. This work was supported in part by an unrestricted gift to Ernest Kun from BiPar Sciences, Inc.

\section{References}

1. Buki KG, Bauer PI, Mendeleyev J, Hakam A and Kun E: Destabilization of $\mathrm{Zn}(\mathrm{II})$ coordination in ADP-ribose transferase (polymerizing) by 6-nitroso-1,2-benzopyrone coincidental with inactivation of the polymerase but not the binding function. FEBS Lett 290: 181-185, 1991.

2. Rice WG, Hillyer CD, Harten B, Schaeffer CA, Dorminy M, Lackey DA III, Kirsten E, Mendeleyev J, Buki KG, Hakam A and Kun E: Induction of endonuclease-mediated apoptosis in tumor cells by C-nitroso substituted ligands of poly(ADP-ribose) polymerase. Proc Natl Acad Sci USA 89: 7702-7707, 1992.

3. Mendeleyev J, Kirsten E, Hakam A, Buki KG and Kun E: Potential chemotherapeutic activity of 4-iodo-3-nitrobenzamide. Metabolic reduction to the 3-nitroso derivative and induction of cell death in tumor cells in culture. Biochem Pharmacol 50: 705-714, 1995.

4. Bauer PI, Mendeleyev J, Kirsten E, Comstock JA, Hakam A, Buki KG and Kun E: Anticancer action of 4-iodo-3-nitrobenzamide in combination with buthionine sulfoximine: inactivation of poly (ADP-ribose) polymerase and tumor glycolysis and the appearance of a poly (ADP-ribose) polymerase protease. Biochem Pharmacol 63: 455-462, 2002.

5. Purnell MR and Whish JD: Novel inhibitors of poly(ADP-ribose) synthetase. Biochem J 185: 775-777, 1980.

6. Kun E, Mendeleyev J and Kirsten E: Aromatic nitro and nitroso compounds and their metabolites useful as anti-viral and antitumor agents. US patent no. 5,464,871, 1995.

7. Kun E and Mendeleyev J: Adenosine diphosphoribose polymerase binding nitroso aromatic compounds useful as retroviral inactivating agents, antiretroviral agents and antitumor agents. US patent no. 5,473,074, 1995 .

8. Pedersen A, Karlsson GB and Rydström J: Proton-translocating transhydrogenase: an update of unsolved and controversial issues. J Bioenerg Biomembr 40: 463-473, 2008.

9. Kun E, Kirsten E, Hakam A, Bauer PI and Mendeleyev J: Identification of poly (ADP-ribose) polymerase-1 as the OXPHOS-generated ATP sensor of nuclei of animal cells. Biochem Biophys Res Commun 366: 568-573, 2008.

10. Kun E, Kirsten E, Hakam A, Bauer PI and Mendeleyev J: Dependence of trans-ADP-ribosylation and nuclear glycolysis on the Arg 34-ATP complex of $\mathrm{Zn}^{2+}$ finger I of poly-ADP-ribose polymerase-1. FEBS Lett 582: 2709-2713, 2008.

11. Bauer PI, Kirsten E, Young LJT, Varadi G, Csonka E, Buki KG, Mikala G, Hu H, Comstock JA, Mendeleyev J, Hakam A and Kun E: Modification of growth related pathways and apparent loss of tumorigenicity of a ras-transformed bovine endothelial cell line by 5 iodo 6 -amino 1,2 benzopyrone $\left(\mathrm{INH}_{2} \mathrm{BP}\right)$. Int $\mathrm{J}$ Oncol 8: 232-252, 1996.

12. Hemann MT and Narita M: Oncogenes and senescence: breaking down in the fast lane. Genes Dev 21: 1-5, 2007.

13. Staab CA, Alander J, Brandt M, Lengovist J, Morgenstern R, Grafström RC and Höög JO: Reduction of S-nitrosoglutathion by alcohol dehydrogenase 3 is facilitated by substrate alcohols via direct cofactor recycling and leads to GSH-controlled formation of glutathione transferase inhibitors. Biochem J 413: 493-504, 2008.

14. Kun E: Fluorocarboxylic acids as enzymatic and metabolic probes. ACS Symposium, Chicago, Biochemistry Involving Carbon Fluorine Bonds. Filler R (ed). Series no. 28. pp1-22, 1976. 